\title{
The Effect of Violent Experience on Burnout among Some Dental Hygienists
}

\author{
Eun-Jeong Jeon ${ }^{1,2}$, Mi Ah $\mathrm{Han}^{3, \dagger}$, Jong Park ${ }^{3}$, and Seong Woo Choi ${ }^{3}$ \\ ${ }^{1}$ Department of Public Health, Graduate School of Health Science, Chosun University, Gwangju 61452, \\ ${ }^{2}$ Yum Kyu-Sun Dental Clinic, Gwangyang 57788, \\ ${ }^{3}$ Department of Preventive Medicine, Chosun University College of Medicine, Gwangju 61452, Korea
}

This study investigated the effect of violent experience on burnout among some dental hygienists. The study subjects were 242 dental hygienists working at dental clinics. Data were collected by self-administered questionnaire including information such as demographics, work-related characteristics, working environment, experience of violence, and burnout. The violence was classified as verbal violence, physical threat, or physical violence committed by dentists, patients, or caregivers. Descriptive analysis, t-test, ANOVA, correlation, and multiple linear regression analysis were performed to examine the factors associated with burnout. The levels of verbal violence, physical threat, and physical violence by dentists were $0.53 \pm 1.26,1.12 \pm 2.70$, and $0.04 \pm 0.42$, respectively. The levels of verbal violence, physical threat, and physical violence by patients and caregivers were $1.50 \pm 1.89,1.41 \pm 2.24$, and $0.24 \pm 1.38$, respectively. The score of burnout was $3.13 \pm 0.43$. Total violence, verbal violence, and physical violence by dentists were positively correlated with burnout. Total violence, verbal violence, and physical threat by patients and caregivers were positively correlated with burnout. In multiple linear regression analysis, the level of physical violence by dentists was positively associated with burnout of dental hygienists $(\beta=0.95, p=0.032)$. The levels of total physical violence $(\beta=0.28, p=0.002)$, verbal violence $(\beta=0.15$, $p<0.001)$, and physical threat $(\beta=0.19, p=0.009)$ by the patients or caregivers were positively associated with burnout of dental hygienists. This study examined the association between violence and burnout among dental hygienists. The level of violence showed positive correlation with burnout. Environment improvement to protect employees from violence and for management of employees who experienced workplace violence are needed to reduce the burnout.

Key Words: Burnout, professional, Dental hygienists, Violence, Workplace violence

\section{Introduction}

In a 2016 survey on the working conditions of health care workers, $47.6 \%$ of the respondents reported that they had experienced violence in workplace (verbal violence $41.0 \%$, physical violence $5.5 \%$, and sexual violence $1.1 \%$ ). With respect to the perpetrators, verbal and physical violence by patients were most common with $70.1 \%$ and $83.7 \%$, respectively, in addition to $36.5 \%$ by doctors and $29.1 \%$ by superiors ${ }^{1}$. The percentage of dental hygienists who had experienced verbal violence while performing their dental duties was $61.2 \%$, with verbal violence being perpetrated by a patient in $67.9 \%$ of cases ${ }^{2}$; by a patient or caregiver in $80.5 \%$; other senior or junior dental hygienist in $52.1 \%$; and dentists in $47.5 \%$ of cases ${ }^{3)}$. Someone who experiences violence feels psychological withdrawal, fear, threat, and embarrassment, and not receiving any institutional help for this may lead to the person suppressing or adjusting his or her own feelings ${ }^{2}$. Moreover, a work environment that is exposed to violence can lead to negative effects, where it can cause not only physical symptoms such as headache and indigestion, but decline in the quality of medical service from decreased productivity, job satisfaction, and job performance ${ }^{4)}$.

Burnout refers to a state of emotional and physical fatigue caused by stress experienced while performing 
one's job, which appears as negative reactions such as emotional exhaustion, fatigue, or depression. Burnout can lead to gradual disinterest in work, decrease in job satisfaction, increase in turnover, and decrease in organizational commitment by the members of the organization, and as a result, it can negatively impact organizational productivity and efficiency ${ }^{5)}$. Moreover, negative psychological symptoms may be experienced from excessive demand for work, which can lead to emotional and physical exhaustion ${ }^{6}$. With respect to burnout-related factors in dental hygienists, level of burnout appeared lower in those with younger age and no religion ${ }^{7)}$, while another study showed that burnout was higher in those with younger age, not married, clinical experience less than 5 years, working in hospital rather than clinic, and having lower job position and pay ${ }^{8)}$.

Among various studies on violent experience and burnout, a study on emergency room nurses found that verbal violence and physical threat were more common than physical violence, while violent experience was positively correlated with burnout ${ }^{9,10}$. Another study on violent experience in dental hygienists found that verbal violence was associated with turnover intention ${ }^{3)}$. As shown, most of the studies on violent experience or burnout have involved nurses, while preceding studies on violence involving dental hygienists have been limited to verbal violence or they also examined hospitals and clinics $^{2,3)}$. However, most dental hygienists work in dental clinics and it has been reported that dental hygienists working in clinics face harsher work environments than in hospitals or general hospitals ${ }^{11)}$, and as such, it is necessary to conduct studies on dental clinics. Accordingly, the present study classified the perpetrators of violence into dentists, patients, or caregivers and divided violent experience into verbal violence, physical threat, and physical violence for investigation of violent experience on burnout among dental hygienists working in clinics.

\section{Materials and Methods}

\section{Subjects and data collection method}

The present study selected 50 clinics by convenience sampling from 45 clinics in $\mathrm{G}$ city and 95 clinics in $\mathrm{S}$ city located in South Jeolla Province. Data collection period was from February 1 to March 15, 2017. Self-reporting questionnaires were distributed to dental hygienists by having the researcher personally visit the clinic or by requesting cooperation from the head dental hygienist at the clinic. Objective of the study was explained prior to collecting the data, and data were collected only from those who consented to participating in the study. To guarantee anonymity and prevent release of data to outside parties, the responses were placed in seal envelopes and retrieved in person. A total of 250 dental hygienists participated, and excluding 8 sets of insufficient responses, a total of 242 sets of data were used for data analysis in the present study. Prior to data collection, approval from the Institutional Review Board at Chosun University Hospital was obtained (IRB no. 2017-01-005).

\section{Survey variables}

\section{1) General characteristics}

The study investigated age, highest education level, religion, current smoking status, frequency of alcohol consumption, and exercise. The study also investigated the number of dentists $(1,2 \sim 5$, and $6 \sim 8)$, number of dental hygienists $(1 \sim 5,6 \sim 10$, and $\geq 11)$, number of patients per day ( $\leq 40,41 \sim 80$, and $\geq 81)$, tenure at current clinic $(\leq 5,6 \sim 10$, and $\geq 11$ years), major duties (all areas, surgery and implants, prosthodontics, orthodontics, management and administrative support, and reception and consultation), job position (regular staff, team leader, manager, and others), workdays per week ( $\leq 5$ and 6 days), night shift (yes and no), and salary level $(\leq 1.5$ million Korean won [KRW], 1.51 2 million KRW, and $\geq 2.01$ million KRW). Moreover, the study also investigated presence of resident safety personnel (yes and no), existence of safety education and guidelines on response measures for when an act of violence occurs, methods for dealing with an act of violence (no action taken, report to a superior, notify the head of the clinic, notify the police, and others), and existence of a post-violence stress intervention program within the workplace. 


\section{2) Work environment}

Work environment was comprised of 3 types of factors: job environment factors, work environment factors, and personal and peer relationship factors ${ }^{12}$. These factors were investigated using a total of 50 questions: work content was investigated with 21 questions on authority on job decisions and job goals; working conditions were investigated with 13 questions on safety infrastructure and compensation; and personal and peer relationships were investigated with 16 questions on relationship with peers and relationship with dentists. The measurement method used a 5-point Likert scale with 5 points for very much; 4 points for much; 3 points for average; 2 points for a little bit; and 1 point for not at all. Higher scores indicated better work environment.

\section{3) Violent experience}

Violent experience was investigated as verbal violence, physical threat, and physical violence with the perpetrators of violence classified as dentist, patient, or caregiver ${ }^{13)}$. A total of 16 questions were used. Verbal violence, such as cursing and yelling, included 3 questions; physical threat, such as assuming a striking pose and displaying threatening expression, included 6 questions; and physical violence, such as hitting, kicking, and pushing, included 7 questions. Violence level was investigated by violent experience and points 0 to 4 were assigned to each item based on violent experience in the past year as none, few times in one year, few times a month, few times a week, and one or more times a day.

\section{4) Burnout}

Burnout is comprised of 3 elements: emotional exhaustion, depersonalization of others, and decreased sense of personal achievement ${ }^{14)}$. Emotional exhaustion refers to depletion of emotional resources or lack of energy, and it was investigated using 9 questions, including those on feeling emotionally depleted and feeling drained. Depersonalization refers to becoming negative and desensitized to work and becoming cynical, and it was investigated using 4 questions, including those on becoming more desensitized to other people and being concerned about work causing emotional dullness. Decreased sense of personal achievement was a category attributed to assessment of work performance due to lack of sense of personal achievement about work and it investigated 8 questions including those on easily understanding the feelings of others (patient, caregiver, and peer) and effectively dealing with problems others have. In total, 21 questions were investigated. The questions were graded on a 5-point Likert scale with 5 points for very much and 1 point for not at all, where higher scores indicated a high intensity of burnout.

\section{Data analysis}

The present study used IBM SPSS Statistics ver. $23.0 \mathrm{~K}$ (IBM Co., Armonk, NY, USA) for analyzing the collected data. Descriptive statistics were used for general, work-related, and violence-related characteristics. Violence experienced by the subjects was derived using frequency, percentage, mean, and standard deviation (SD), while burnout and work environment were expressed as mean and SD. Differences in general, work-related, and violence-related characteristics were analyzed via t-test and analysis of variance, while Tukey test was used for post hoc testing on variables that showed significant differences. Pearson correlation analysis was used to examine correlations among violent experience, work environment, and burnout. For investigation of factors that influence burnout, multiple linear regression analysis was performed on items that showed significance probability of $<0.1$ in the simple analyses. Multiple linear regression analysis was performed according to the type of perpetrator: dentists, patients, or caregivers. Moreover, violent experience included all violence, verbal violence, physical threat, and physical violence. The statistical significance level was set to $\mathrm{p}<0.05$.

\section{Results}

\section{Violence experience, burnout, and work environment}

Experience of violence from a dentist in the past year was $31.4 \%$ in total, and the percentages based on the type of violence were $22.7 \%, 28.1 \%$, and $1.7 \%$ for verbal violence, physical threat, and physical violence, respectively. Level of violence perpetrated by a dentist was 
Table 1. Type of Violence and Frequency

\begin{tabular}{lccccc}
\hline \multirow{2}{*}{ Classification } & \multicolumn{2}{c}{ Dentist } & & \multicolumn{2}{c}{ Patient and caregiver } \\
\cline { 2 - 3 } \cline { 5 - 6 } & Experienced no. $(\mathrm{n}=242)$ & Level of violence & & Experienced no. $(\mathrm{n}=242)$ & Level of violence \\
\hline Total & $76(31.4)$ & $1.69 \pm 3.81$ & & $139(57.4)$ & $3.15 \pm 4.60$ \\
Verbal violence & $55(22.7)$ & $0.53 \pm 1.26$ & & $134(55.4)$ & $1.50 \pm 1.89$ \\
Physical threat & $68(28.1)$ & $1.12 \pm 2.70$ & & $116(47.9)$ & $1.41 \pm 2.24$ \\
Physical violence & $4(1.7)$ & $0.04 \pm 0.42$ & & $13(5.4)$ & $0.24 \pm 1.38$ \\
\hline
\end{tabular}

Values are presented as $\mathrm{n}(\%)$ or mean \pm standard deviation.

Table 2. Burnout and Work Environment

\begin{tabular}{lc}
\hline \multicolumn{1}{c}{ Characteristic } & Mean \pm standard deviation \\
\hline Burnout & $3.13 \pm 0.43$ \\
Emotional weariness & $3.01 \pm 0.73$ \\
Depersonalization & $3.54 \pm 0.73$ \\
Decrease of personal achievement & $2.82 \pm 0.46$ \\
Work environment & $3.14 \pm 0.42$ \\
Work context & $3.28 \pm 0.49$ \\
Work conditions & $3.01 \pm 0.58$ \\
Relationship with coworkers & $3.13 \pm 0.37$ \\
\hline
\end{tabular}

$1.69 \pm 3.81$ in total and $0.53 \pm 1.26,1.12 \pm 2.70$, and $0.04 \pm 0.42$ for verbal violence, physical threat, and physical violence, respectively. Experience of violence from a patient or caregiver was $57.4 \%$ in total and $55.4 \%$, $47.9 \%$, and $5.4 \%$ for verbal violence, physical threat, and physical violence, respectively. Level of violence perpetrated by a patient and caregiver was $3.15 \pm 4.60$ in total and $1.50 \pm 1.89,1.41 \pm 2.24$, and $0.24 \pm 1.38$ for verbal violence, physical threat, and physical violence, respectively (Table 1).

The mean burnout score was $3.13 \pm 0.43$, and in the sub-categories, scores for emotional exhaustion, depersonalization, and decreased sense of personal achievement were $3.01 \pm 0.73,3.54 \pm 0.73$, and $2.82 \pm 0.46$, respectively. The mean work environment score was $3.14 \pm 0.42$, and in the sub-categories, scores for work content, working conditions, and personal and peer relationships were $3.28 \pm 0.49$, $3.01 \pm 0.58$, and $3.13 \pm 0.37$, respectively (Table 2 ).

\section{Burnout according to subject characteristics}

There were significant differences in burnout based on the number of dental hygienists with scores of $2.83 \pm 0.47$, $2.67 \pm 0.48$, and $2.55 \pm 0.48$ for $6 \sim 10,1 \sim 5$, and $\geq 11$, respectively $(p=0.014)$, and post hoc test results showed that burnout was significantly higher when the number of dental hygienists was $6 \sim 10$ as compared to $\geq 11$ (p $<0.05)$. There were differences in burnout based on job position with scores of $2.68 \pm 0.48,2.55 \pm 0.51,2.40 \pm 0.51$, and $2.76 \pm 0.30$ for regular staff, team leader, manager, and others, respectively $(\mathrm{p}=0.047)$, and post hoc test results showed that burnout was significantly higher in regular staff as compared to managers $(\mathrm{p}<0.05)$ (Table 3$)$.

\section{Correlation among violence experience, work environment, and burnout}

Violence perpetrated by a dentist was significantly positively correlated with burnout $(\mathrm{r}=0.133, \mathrm{p}=0.039)$, and with respect to types of violence, verbal violence $(\mathrm{r}=0.171$, $\mathrm{p}=0.008)$ and physical violence $(\mathrm{r}=0.171, \mathrm{p}=0.008)$ showed significantly positive correlation with burnout. Violence perpetrated by a patient or caregiver was significantly positively correlated with burnout $(\mathrm{r}=0.202, \mathrm{p}=0.002)$, and with respect to types of violence, verbal violence $(r=0.208$, $\mathrm{p}=0.001)$ and physical threat $(\mathrm{r}=0.183, \mathrm{p}=0.004)$ showed significantly positive correlation with burnout. Work environment was significantly negatively correlated with burnout $(\mathrm{r}=-0.543, \mathrm{p}<0.001)$, and with respect to sub-categories, job environment $(\mathrm{r}=-0.512, \mathrm{p}<0.001)$, work environment $(\mathrm{r}=-0.411, \mathrm{p}<0.001)$, and personal and peer relationships $(\mathrm{r}=-0.552, \mathrm{p}<0.001)$ showed significantly negative correlation with burnout (Table 4).

\section{Association between violence and burnout}

In the case of violence by a dentist, increase in physical violence resulted in significant increase in burnout $(\beta=0.95, p=0.032)$. However, all violence $(\beta=0.03$, $\mathrm{p}=0.796)$, verbal violence $(\beta=0.10, \mathrm{p}=0.126)$, and physical threat $(\beta=-0.04, p=0.479)$ did not show significant 
Table 3. Burnout Level by Subject's Characteristics

\begin{tabular}{|c|c|c|c|c|c|}
\hline Characteristic & Classification & Subject $(n=242)$ & Burnout & $\mathrm{t} / \mathrm{F}$ & p-value (Tukey) \\
\hline \multirow[t]{4}{*}{ Age (y) } & $\leq 25$ & $66(27.3)$ & $2.58 \pm 0.50$ & 2.306 & 0.077 \\
\hline & $26 \sim 30$ & $90(37.2)$ & $2.68 \pm 0.47$ & & \\
\hline & $31 \sim 35$ & $44(18.2)$ & $2.76 \pm 0.40$ & & \\
\hline & $\geq 36$ & $42(17.4)$ & $2.53 \pm 0.54$ & & \\
\hline \multirow[t]{2}{*}{ Education } & College & $231(95.5)$ & $2.65 \pm 0.47$ & 0.548 & 0.595 \\
\hline & $>$ College & $11(4.5)$ & $2.52 \pm 0.77$ & & \\
\hline \multirow[t]{4}{*}{ Religion } & Christian & $52(21.5)$ & $2.72 \pm 0.46$ & 2.248 & 0.083 \\
\hline & Buddhist & $17(7.0)$ & $2.42 \pm 0.71$ & & \\
\hline & None & $161(66.5)$ & $2.66 \pm 0.46$ & & \\
\hline & Other & $12(5.0)$ & $2.46 \pm 0.56$ & & \\
\hline \multirow[t]{2}{*}{ Current smoking } & No & $230(95.0)$ & $2.65 \pm 0.47$ & 0.443 & 0.666 \\
\hline & Yes & $12(5.0)$ & $3.12 \pm 0.41$ & & \\
\hline \multirow[t]{4}{*}{ Drinking frequency } & None & $33(13.6)$ & $2.60 \pm 0.33$ & 0.246 & 0.864 \\
\hline & $1 / \mathrm{mo}$ & $75(31.0)$ & $2.64 \pm 0.48$ & & \\
\hline & $2 \sim 4 / \mathrm{mo}$ & $102(42.1)$ & $2.64 \pm 0.52$ & & \\
\hline & $\geq 2 / \mathrm{wk}$ & $32(13.2)$ & $2.70 \pm 0.53$ & & \\
\hline \multirow[t]{4}{*}{ Exercise frequency } & None & $122(50.4)$ & $2.67 \pm 0.47$ & 0.649 & 0.584 \\
\hline & $1 / \mathrm{mo}$ & $37(15.3)$ & $2.60 \pm 0.44$ & & \\
\hline & $2 \sim 4 / \mathrm{mo}$ & $30(12.4)$ & $2.55 \pm 0.48$ & & \\
\hline & $\geq 2 \mathrm{wk}$ & $53(21.9)$ & $2.67 \pm 0.55$ & & \\
\hline \multirow[t]{3}{*}{ Number of dentists } & 1 & $114(47.1)$ & $2.66 \pm 0.47$ & 0.274 & 0.760 \\
\hline & $2 \sim 5$ & $77(31.8)$ & $2.61 \pm 0.53$ & & \\
\hline & $6 \sim 8$ & $51(21.1)$ & $2.66 \pm 0.46$ & & \\
\hline \multirow[t]{3}{*}{ Number of dental hygienist } & $1 \sim 5^{\mathrm{a}}$ & $112(46.3)$ & $2.67 \pm 0.48$ & 4.372 & 0.014 \\
\hline & $6 \sim 10^{\mathrm{b}}$ & $32(13.2)$ & $2.83 \pm 0.47$ & & $(b>c)$ \\
\hline & $\geq 11^{\mathrm{c}}$ & $98(40.5)$ & $2.55 \pm 0.48$ & & \\
\hline \multirow[t]{3}{*}{ Number of patient visits $(1 \mathrm{~d})$} & $\leq 40$ & $118(48.8)$ & $2.63 \pm 0.46$ & 2.788 & 0.064 \\
\hline & $41 \sim 80$ & $53(21.9)$ & $2.77 \pm 0.56$ & & \\
\hline & $\geq 81$ & $71(29.3)$ & $2.56 \pm 0.45$ & & \\
\hline \multirow[t]{3}{*}{ Clinic career (y) } & $\leq 5$ & $173(71.5)$ & $2.67 \pm 0.49$ & 2.863 & 0.059 \\
\hline & $6 \sim 10$ & $46(19)$ & $2.67 \pm 0.42$ & & \\
\hline & $\geq 11$ & $23(9.5)$ & $2.41 \pm 0.55$ & & \\
\hline \multirow[t]{5}{*}{ Working field } & All work & $161(66.5)$ & $2.63 \pm 0.46$ & 1.579 & 0.180 \\
\hline & Surgery \& implant & $14(5.8)$ & $2.46 \pm 0.42$ & & \\
\hline & Prosthetic & $17(7.0)$ & $2.85 \pm 0.39$ & & \\
\hline & Orthodontic & $27(11.2)$ & $2.72 \pm 0.57$ & & \\
\hline & Reception & $23(9.5)$ & $2.56 \pm 0.60$ & & \\
\hline \multirow[t]{4}{*}{ Job position } & Staff $^{\mathrm{a}}$ & $189(78.1)$ & $2.68 \pm 0.48$ & 2.693 & 0.047 \\
\hline & Team leader ${ }^{\mathrm{b}}$ & $23(9.5)$ & $2.55 \pm 0.51$ & & $(a>c)$ \\
\hline & Manager $^{\mathrm{c}}$ & $23(9.5)$ & $2.40 \pm 0.51$ & & \\
\hline & Other $^{\mathrm{d}}$ & $6(2.5)$ & $2.76 \pm 0.30$ & & \\
\hline \multirow[t]{2}{*}{ Working day (1 wk) } & $\leq 5$ & $125(51.7)$ & $2.63 \pm 0.49$ & -0.053 & 0.591 \\
\hline & 6 & $117(48.3)$ & $2.66 \pm 0.49$ & & \\
\hline \multirow[t]{2}{*}{ Night duty } & Yes & $126(52.1)$ & $2.69 \pm 0.47$ & 1.568 & 0.118 \\
\hline & No & $116(47.9)$ & $2.60 \pm 0.50$ & & \\
\hline \multirow[t]{3}{*}{ Monthly income (10,000 KRW) } & $\leq 150$ & $80(33.1)$ & $2.61 \pm 0.45$ & 1.855 & 0.159 \\
\hline & $151 \sim 200$ & $113(46.7)$ & $2.70 \pm 0.48$ & & \\
\hline & $\geq 201$ & $49(20.2)$ & $2.56 \pm 0.54$ & & \\
\hline \multirow[t]{2}{*}{ Safety guard } & Yes & $6(2.5)$ & $2.56 \pm 0.69$ & -1.378 & 0.226 \\
\hline & No & $236(97.5)$ & $2.65 \pm 0.48$ & & \\
\hline
\end{tabular}


Table 3. Continued

\begin{tabular}{|c|c|c|c|c|c|}
\hline Characteristic & Classification & Subject $(n=242)$ & Burnout & $\mathrm{t} / \mathrm{F}$ & p-value (Tukey) \\
\hline \multirow[t]{2}{*}{ Safety education for violence } & Yes & $30(12.4)$ & $2.55 \pm 0.41$ & -1.076 & 0.283 \\
\hline & No & $212(87.6)$ & $2.66 \pm 0.48$ & & \\
\hline \multirow[t]{2}{*}{ Guideline for violence } & Yes & $18(7.4)$ & $2.46 \pm 0.52$ & -1.641 & 0.102 \\
\hline & No & $224(92.6)$ & $2.66 \pm 0.48$ & & \\
\hline \multirow[t]{5}{*}{ Method of dealing with violence } & Just let it pass & $7(2.9)$ & $3.11 \pm 0.69$ & 2.215 & 0.068 \\
\hline & Inform the superior & $98(40.5)$ & $2.60 \pm 0.45$ & & \\
\hline & Inform the dentist & $103(42.6)$ & $2.67 \pm 0.50$ & & \\
\hline & Call the police & $20(8.3)$ & $2.57 \pm 0.38$ & & \\
\hline & Other & $14(5.8)$ & $2.55 \pm 0.59$ & & \\
\hline \multirow[t]{2}{*}{ Stress management program } & Yes & $4(1.7)$ & $3.09 \pm 0.72$ & 1.891 & 0.060 \\
\hline & No & $238(98.3)$ & $2.63 \pm 0.48$ & & \\
\hline
\end{tabular}

Values are presented as $\mathrm{n}(\%)$ or mean \pm standard deviation.

KRW: Korean won.

Table 4. Correlations between Violence Experience, Work Environment and Burnout

\begin{tabular}{lc}
\hline Characteristic & Burnout \\
\hline Violence & \\
Dentist & $0.133(0.039)$ \\
Total violence & $0.171(0.008)$ \\
Verbal violence & $0.082(0.203)$ \\
Physical threat & $0.171(0.008)$ \\
Physical violence & \\
Patient and caregiver & $0.202(0.002)$ \\
Total violence & $0.208(0.001)$ \\
Verbal violence & $0.183(0.004)$ \\
Physical threat & $0.093(0.151)$ \\
Physical violence & \\
Work environment & $-0.543(<0.001)$ \\
Total work environment & $-0.512(<0.001)$ \\
Work context & $-0.411(<0.001)$ \\
Work conditions & $-0.552(<0.001)$ \\
Relationship with coworkers &
\end{tabular}

Values are expressed as correlation coefficient (p-value).

association with burnout. In the case of violence by a patient or caregiver, all violence $(\beta=0.28, p=0.002)$, verbal violence $(\beta=0.15, p<0.001)$, and physical threat $(\beta=0.19$, $\mathrm{p}=0.009$ ) showed significant association with burnout (Table 5).

\section{Discussion}

The present study investigated the current state of violent experience in dental hygienists working in dental clinics and analyzed its effect on burnout. In the case of violence perpetrated by a dentist, $28.1 \%, 22.7 \%$, and $1.7 \%$ of respondents had experienced physical threat, verbal violence, and physical violence, respectively. In the case of violence perpetrated by a patient or caregiver, $55.4 \%$, $47.9 \%$, and $5.0 \%$ experienced verbal violence, physical threat, and physical violence, respectively. Therefore, physical threat was the most common form of violence perpetrated by a dentist, and verbal violence was the most common form of violence perpetrated by a patient or caregiver. As shown, verbal violence was perpetrated more often by a patient or caregiver than a dentist, which was consistent with another study on dental hygienists that reported perpetrators of verbal violence being a patient in $67.9 \%$ of cases and dentist in $21.1 \%$ of the cases ${ }^{2)}$. A previous study on nurses reported that nurse who had verbal violence experience was $95.9 \%^{15}$, and thus the findings in the present study were consistent with another study that reported verbal experience was lower among dental hygienists than nurses ${ }^{3)}$. It is believed that this is because dental hygienists mostly interact with a patient or caregiver on an outpatient basis, but nurses deal with inpatients, which requires relatively more time for care and caring for patients with severe conditions. Moreover, nurses may be exposed more to violent situations because of the nature of their work which requires them to work as a team with various medical personnel and workers from other departments who must respond immediately and quickly to emergency situations ${ }^{16)}$. Moreover, it is also believed that there are differences in violent experience 
Table 5. Violence and Burnout Using Multiple Linear Regression

\begin{tabular}{clrrrr}
\hline \multicolumn{1}{c}{ Attacker } & Type of violence & \multicolumn{1}{c}{$\beta(\mathrm{SE})$} & $\mathrm{p}$-value & $\mathrm{F}(\mathrm{p})$ & $\mathrm{R}^{2}$ \\
\hline Dentist & Total violence & $0.03(0.12)$ & 0.796 & $6.280(<0.001)$ & 0.387 \\
& Verbal violence & $0.10(0.06)$ & 0.126 & $6.450(<0.001)$ & 0.393 \\
& Physical threat & $-0.04(0.06)$ & 0.479 & $6.312(<0.001)$ & 0.388 \\
\multirow{3}{*}{ Patient and caregiver } & Physical violence & $0.95(0.44)$ & 0.032 & $6.622(<0.001)$ & 0.399 \\
& Total violence & $0.28(0.09)$ & 0.002 & $6.972(0.001)$ & 0.412 \\
& Verbal violence & $0.15(0.04)$ & $<0.001$ & $7.241(0.001)$ & 0.421 \\
& Physical threat & $0.19(0.07)$ & 0.009 & $6.793(0.001)$ & 0.406 \\
& Physical violence & $0.15(0.14)$ & 0.294 & $6.357(0.001)$ & 0.390 \\
\hline
\end{tabular}

Adjusted for age, religion, number of hygienists, number of patients, clinic career, job position, methods for dealing with violence, stress management program and working environment.

due to differences in patient cognition and job perception based on job types of medical workers ${ }^{17,18}$.

In the present study, percentages of violent experience were $2.5 \%$ when resident safety personnel were present; $12.4 \%$ when safety training for responding to violent situations was available; $7.4 \%$ when guidelines for dealing with violence were available; and $1.7 \%$ when stress intervention program after violent episode was available. A study on nurses found that violent experience was $11.6 \%$ when violence prevention and response education was given and there were high demands for assigning enough safety personnel and establishing policies for violence prevention ${ }^{14)}$. Moreover, most had answered that they responded to a violent episode by tolerating or ignoring $\mathrm{it}^{15)}$, indicating that institutional system and support for dealing with violence was lacking. However, not responding well to violent situations and not properly dealing with stress from such situations may lead to post-traumatic stress or job turnover ${ }^{19)}$, and thus, future considerations are needed on assignment of safety personnel based on the size of the institution, prevention through application of violence prevention programs, intervention programs after violent episodes, and reduction of post-traumatic stress.

In the present study, the overall burnout score among the subjects was $3.13 \pm 0.43$, and for the sub-categories, the scores were $3.01 \pm 0.73$ for emotional exhaustion, $3.54 \pm 0.73$ for depersonalization, and $2.82 \pm 0.46$ for decreased sense of personal achievement, showing the highest score for depersonalization. In the case of depersonalization, stronger expression of emotions led to decrease in burnout, and thus, organizational consideration and measures are needed to encourage one to freely express one's emotions or thoughts, and since peer support has a moderating effect on burnout, organizational stability and trust should be formed through support by superiors or peers when problems or difficulties occur during the care giving process by dental hygienists ${ }^{20)}$.

Analysis on the correlation between violent experience and burnout showed that violent experience was significantly positively correlated with burnout, which was consistent with a study that showed positive correlation between violent experience and burnout among emergency room nurses ${ }^{10)}$ and another study on violent experience and burnout among 911 emergency personnel $^{21)}$. The multiple regression analysis showed that when the perpetrator was a dentist, only physical violence had an impact on burnout, while when the perpetrator was a patient or caregiver, all violence, verbal violence, and physical threat had an impact on burnout. A previous study that assessed post-traumatic stress according to violence reported that there were differences in the level of post-traumatic stress based on the type of perpetrator, where the level of post-traumatic stress was high when the perpetrator was a doctor ${ }^{19)}$. Therefore, when considering the impact of violence and response measures, it would be necessary to take into account the types of perpetrator. For violence perpetrated by a dentist, only physical violence had an impact on burnout in the multiple regression analysis. A previous study on nurses reported that among verbal violence, especially disrespectful speech by medical staff had an impact on burnout, and in medical 
settings where disrespectful speech was prevalent not only by patients and caregivers but also among medical staff, the medical staff members often did not recognize that disrespectful speech qualified as verbal violence. Therefore, it is necessary for hospitals to establish systematic measures for an organizational culture that promote mutual respect among medical staff and recognition of peers ${ }^{22)}$. In the case of a patient or caregiver, all forms of violence, except serious physical violence, had an impact on burnout. Verbal violence within the hospital had an impact on physical and emotional damage, as well as job turnover, and most of those who experienced verbal violence felt anger, sadness, disappointment, and fear; they also showed an emotional response of being fearful of providing patient care ${ }^{23)}$. Violence caused decline in job performance and motivation, which could lead to inefficient job performance, increased turnover, and decline in quality of patient care due to burnout ${ }^{4)}$. Unlike medical staff, patients or caregivers had an impact on burnout even with low violence levels, which was attributed to patients not recognizing or respecting dental hygienists as professionals and perceiving them as someone to whom complaint or anger can be directed ${ }^{2)}$. With the recent increase in patient care that a dental hygienist can administer alone after instructions from a dentist, such as scaling, fluoride application, tooth filling, and oral health education, there is a greater need for responsive measures against violence from patients or caregivers.

Harsher work environment resulted in higher burnout, and a previous study reported that poor work environment, such as high demand for work efficiency, working long hours, environment without assistants, and lack of leisure time and hospital management support caused an increase in burnout among dental hygienists ${ }^{24)}$. Another study also reported significantly negative correlation between work environment and burnout, which was the same as decline in work environment resulting in higher burnout in the present study ${ }^{25)}$. When the work scope of dental hygienists was clearly defined and their sense of personal achievement was increased, their job satisfaction, job performance, and productivity increased as well ${ }^{26}$, and work environment that can reduce burnout should be created for dental hygienists working in dental hospitals and clinics by establishing an adequate compensation system and broadening their mutual understanding by accurately identifying conflicts that may arise during their work activities $^{27)}$

Investigation of factors other than violence that impact burnout showed that job position was associated with a stress intervention program after a violent episode and methods for dealing with violent episodes. In the present study, burnout level was high even when intervention programs were available, but because the present study was a cross-sectional study, causal relationship could not be accurately identified. However, it is highly probable that stress intervention programs were applied due to the subjects being exposed to high levels of violence and feeling significant amounts of stress. Another study reported that when medical personnel suffer a violent episode, victims should be supported and encouragement should be given with more humane interest so that they can respond more positively and actively to anger and pain that they feel; efforts by the manager and intervention for problem solving should be directed towards managing the emotional response from the moment the violent episode occurs ${ }^{28)}$. It is believed that continued studies are needed on future responses and alternatives for dealing with violence experienced by dental hygienists.

The limitations in the present study included the fact that since it was a cross-sectional study, causal relationship between burnout and related factors could not be accurately identified. Moreover, since the subjects were limited to those from a specific region, there are limitations in generalizing the results for all dental hygienists. Despite such limitations, the present study was significant in that the study included only dental hygienists who work in a dental clinic, unlike most other studies that also included dental hospitals. Moreover, previous studies on dental hygienists were limited to verbal violence, but the present study investigated the overall violent experience by examining verbal violence, physical threat, and physical violence with perpetrators of violence divided into dentists, patients, or caregivers. Previous studies on burnout associated with violence in medical institutions mostly examined nurses, and thus, the 
present study was significant in that it identified the effects of violent experience on burnout among dental hygienists and analyzed the associations between these factors.

Violent experience among dental hygienists increased their burnout, with differences found based on the type of perpetrator, while burnout was also associated with the work environment of the medical institution. Therefore, future studies should investigate the cause of violence suffered by dental hygienists according to the type of perpetrator, responses after violent episodes, and associations of work environment factors that affect burnout, so that measures to reduce workplace violence can be established to improve the quality of the work environment and human resources management.

\section{Acknowledgements}

This article is a condensed form of the first author's master's thesis from Chosun University.

\section{References}

1. Lss JS, Chung HJ, Co HM, Kim HJ: Health care workers survey. Korean Health and Medical Worker's Union, Seoul, pp.55-56, 2016.

2. Moon HJ, Han YS, Cho YS, Lim SR: A study on verbal abuse experience and coping strategies of dental hygienist. J Dent Hyg Sci 15: 348-354, 2015.

3. Lee JH, Choi JM, Lee YA: The help of experienced dental hygienists turnover verbal abuse and emotional reaction, and the resulting relationship. J Dent Hyg Sci 14: 563-570, 2014.

4. Son YJ, Gong HH, You MA, Kong SS: Relationships between workplace violence experience and posttraumatic stress symptoms, resilience in clinical nurses. J Korean Data Anal Soc 17: 515-530, 2015.

5. Kang JS, Lim JY: Effects of clinical nurses' resilience on job stress and burnout. J Korean Cont Assoc 15: 263-273, 2015.

6. Jeong KY, Han OS: A study on emotional labor, emotional burnout, turnover intention of dental hygienist. J Dent Hyg Sci 15: 280-286, 2015.

7. Oh HS: Relationship between emotional labor, burnout and turnover intention in the dental hygienists. J Korean Sci Dent Hyg 15: 641-648, 2015.
8. Han YK, Kim HH: The relationship among burnout, compassion fatigue, compassion satisfaction and social support of clinical dental hygienists. J Dent Hyg Sci 14: 256-263, 2014

9. Jung HY, Kim SO, Kim IS: Factors influencing burnout in emergency room nurses. Korean J Occup Health Nurs 23: $1-10,2014$.

10. Sung MH: Relationship of the experience of violence to burnout and job satisfaction in emergency department nurses. J Korean Clin Nurs Res 14: 83-92, 2008.

11. Yoo JS, Kim YM, Han GS: A study on work environments for dental hygienists: focusing on kind of workplace, career and service area. J Korean Acad Dent Hyg Educ 7: 135-151, 2007.

12. Lee NS: Factors affecting the job satisfaction of dental hygienists. Unpublished master's thesis, Korea University, Seoul, 2007.

13. Jeon HS: The effect of the violence experiences of the emergency room nurse on burnout and job satisfaction. Unpublished maser's thesis, Kyung Hee University, Seoul, 2012.

14. Yang JH, Jung HY: Relationship betwwn violence response, coping, and burnout among emergency department nurses. J Korean Acad Fundam Nurs 16: 103-111, 2009.

15. Jung HJ, Lee YS: Nurses's experiences of verbal abuse in hospital setting. Korean J Health Commun 6: 118-126, 2011.

16. Kim JW, Ko SJ, Shin SH: The effects of verbal violence experience, social support, and coping patterns on job stress among operating room nurses, J Korean Clin Nurs Res 22: 38-45, 2016.

17. Chung WG, Son AR, Jung HR, et al.: Cognition and perception of community members about dental hygienist's job. J Korean Acad Dent Hyg Educ 6: 403-417, 2006.

18. Park SY, Won YS: Recognition of health care workers for dental hygienists. Korean J Health Serv Manage 6: 127-140, 2012.

19. Yi H, Shin MK: Factors affecting post traumatic stress disorder of the verbal violence experienced nurses. J Korea Soc Health Inform Stat 38: 15-25, 2013.

20. Kim JY: Influence of emotional labor on job burnout in dental hygienists: the moderating effect of employee support. J Korea Soc Dent Hyg 16: 751-758, 2016.

21. Kim JH, Uhm DC, Kim EA: Correlation between violence, 
burnout and self-esteem of 119 rescue workers. J Korea Acad Ind Coop Soc 11: 4433-4440, 2010.

22. Kang MJ, Park IS: Types of violence and coping methods experienced general hospital nurses. J Korea Clin Nurs Res 21: 92-104, 2015.

23. Arnetz JE, Arnetz BB: Violence towards health care staff and possible effects on the quality of patient care. Soc Sci Med 52: 417-427, 2001.

24. Park JH: Burnout and job satisfaction among dental hygienists in some legions. J Korean Acad Dent Hyg Educ 9: 569-579, 2009.
25. Choi KJ, Han SS: The influence of the job stress, job satisfaction and social support of clinical nurse's burnout. Korea J East West Nurs Res 19: 55-61, 2013.

26. Kwon JY, Lee SY: Relationship of between task performance, job satisfaction, and organizational contribution of dental hygienists. J Dent Hyg Sci 16: 302-309, 2016.

27. Jeong SR, Jang JE: The correlation between conflict level within the organization and job satisfaction of the dental hygienist. J Dent Hyg Sci 15: 38-45, 2015.

28. Kim JI, Kim TS: Violence episodes and turnover among clinical nurses. J Korean Acad Nurs Adm 10: 427-436, 2004. 